\title{
Nitro compounds as useful reagents for the synthesis of dicarbonyl derivatives
}

\author{
Roberto Ballini,* Luciano Barboni, Dennis Fiorini, Alessandro Palmieri, and Marino \\ Petrini*
}

Dipartimento di Scienze Chimiche, Università di Camerino, via S. Agostino, 1, 62032 Camerino Italy

E-mail: roberto.ballini@unicam.it; marino.petrini@unicam.it

This review is dedicated to Prof. Giuseppe Bartoli on the occasion of his $65^{\text {th }}$ birthday

\begin{abstract}
The reaction of functionalized nitroalkanes with electrophiles such as Michael acceptors and aldehydes is one of the most exploited procedures for the synthesis of new carbon-carbon bonds. Conversion of the nitro group in the adduct into a carbonyl derivative usually provides a rapid entry to dicarbonyl systems that are amenable to further synthetic transformation into a plethora of important targets.
\end{abstract}

Keywords: Conjugate addition, cycloalkanones, dicarbonyl derivatives, Nef reaction, nitroaldol reaction, nitroalkanes

\section{Contents}

1. Introduction

2. 1,2-Dicarbonyl and 1,3-dicarbonyl derivatives

3. 1,4-Dicarbonyl derivatives

3.1. Synthesis of 1,4-dicarbonyls using a conjugate addition-Nef reaction

3.2. Synthesis of 1,4-dicarbonyls using a nitroaldol reaction

4. 1,5-Dicarbonyl and 1,6-dicarbonyl derivatives

5. $\alpha, \omega$-Dicarbonyl derivatives by ring cleavage of 2-nitrocycloalkanones.

6. Tunable syntheses of $1, n$-dicarbonyl derivatives.

7. Tricarbonyl derivatives.

8. Conclusions. 


\section{Introduction}

Polyfunctionalized derivatives containing a dicarbonyl moiety are valuable intermediates in organic synthesis since they can be transformed into a plethora of important target compounds such as cyclopentenones, furans, pyrroles, thiophenes and other heterocyclic systems. ${ }^{1-8}$ Classical methods for the synthesis of dicarbonyl derivatives usually involve an addition reaction of a metal enolate with a carboxylic acid ester or with a Michael acceptor. The former procedure is also referred as the Claisen condensation and provides a straightforward entry to 1,3dicarbonyl derivatives, ${ }^{9,10}$ and the latter leads to the formation of 1,5 -dicarbonyl frameworks. ${ }^{11} \mathrm{~A}$ viable access to 1,4-dicarbonyl systems using such procedures is not an easy task since it would involve a conjugate addition between an umpoled acyl anion synthon and a Michael acceptor. Nitroalkanes are a valuable source of stabilized carbanions since the high electron-withdrawing power of the nitro group provides an outstanding enhancement of the hydrogen acidity at the $\alpha$ position (cf. p $k_{\mathrm{a}} \mathrm{MeNO}_{2}=10$ ). ${ }^{12-16}$ Nitronate anions 2 that can be generated from nitroalkanes 1 using a wide range of bases, act as carbon nucleophiles with common electrophiles including haloalkanes, ${ }^{17}$ aldehydes, ${ }^{18,19}$ and Michael acceptors, ${ }^{20}$ leading to carbon-carbon bond formation (Scheme 1).

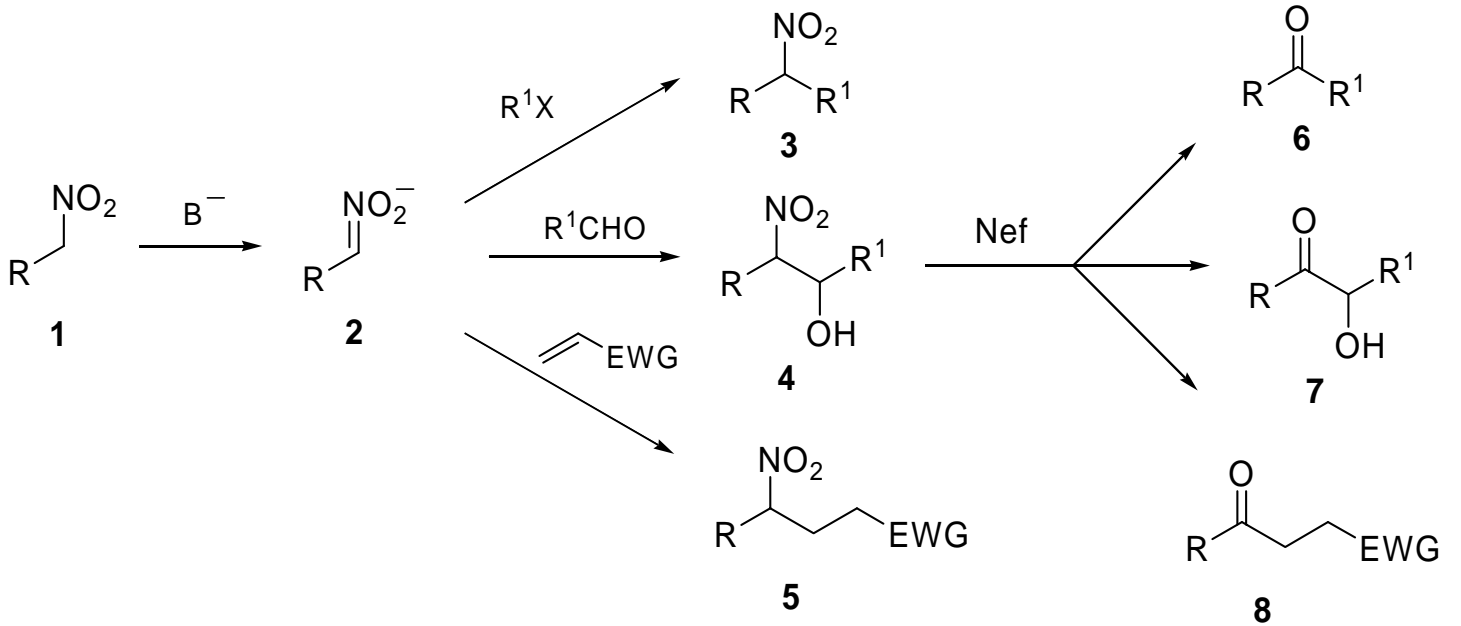

\section{Scheme 1}

A further option is represented by the conversion of the nitro group into a carbonyl group, leading to carbonyl derivatives 6-8, a transformation widely known as the Nef reaction, that ultimately leads to a reversal in the polarity of the neighboring carbon atom from nucleophilic to electrophilic. ${ }^{21,22}$ The original procedure for the nitro to carbonyl transformation, as described by Nef, was essentially the hydrolysis in strongly acidic conditions of a nitronate salt produced by basic treatment of a nitroalkane. The harsh conditions in which this conversion is usually carried out $(\mathrm{pH}<1)$ have spurred on the development of alternative methods that can be performed in 
oxidative, reductive, as well as almost neutral, conditions. The aim of this review is to discuss the utilization of nitroalkanes as nucleophilic reagents for the synthesis of dicarbonyl derivatives using a strategy involving a nucleophilic addition of the nitro derivative followed by a nitro to carbonyl conversion. Although these procedures are usually accomplished by a two-step synthesis, there are several examples in which this overall transformation can be carried out in a 'one-pot' system thus realizing a more efficient process.

\section{1,2-Dicarbonyl and 1,3-dicarbonyl derivatives}

Nitro compounds have been used only occasionally in the synthesis of 1,2- and 1,3-dicarbonyl derivatives. The oxidative Nef reaction carried out on the products of nitroaldol addition such as $\mathbf{9}$ affords $\alpha$-keto acids $\mathbf{1 0}$ or aldehydes using molecular oxygen in the presence of copper salts (Scheme 2). ${ }^{23}$

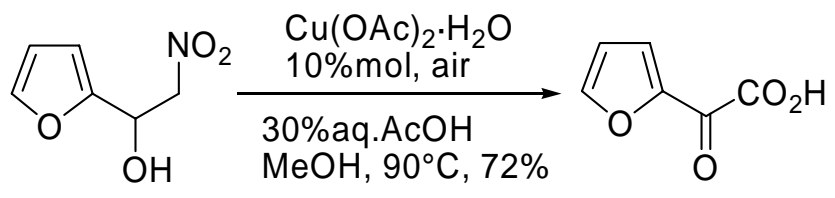

9

10

\section{Scheme 2}

Cyclic nitroalkenes can be converted into $\alpha$-nitro epoxides 11 using metal salts of $t$-butyl hydroperoxide. Cleavage of the epoxide ring in acidic conditions directly affords 1,2-dicarbonyl derivatives 12 (Scheme 3). ${ }^{24}$

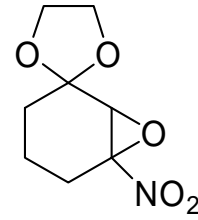

11

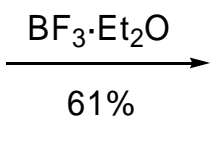

12

\section{Scheme 3}

The reaction of the nickel acylate complex 14 with nitroalkenes such as $\mathbf{1 3}$ gives the corresponding addition products 15 that, by treatment with iodine, afford the 1,3-dicarbonyl derivatives 16. Iodine provides cleavage of the nickel adduct and of the nitronate anion in a tandem process (Scheme 4). ${ }^{25}$

The reduction of nitroalkenes such as $\mathbf{1 7}$ with $\mathrm{Bu}_{3} \mathrm{SnH}$ occurs in neutral conditions, giving the corresponding stannylnitronates $18 .^{26}$ These nitronates can be oxidized to the parent carbonyl 
derivatives using ozone at low temperatures. This procedure is particularly effective in the synthesis of $\beta$-lactam building blocks 19 (Scheme 5).

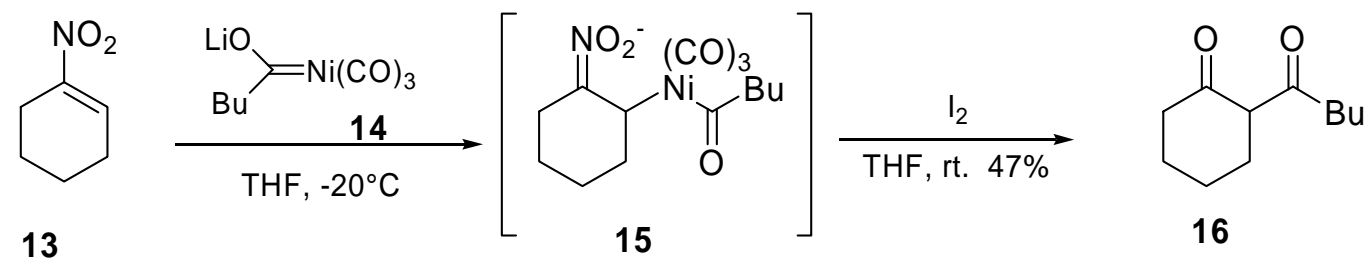

\section{Scheme 4}<smiles>[R]C1C(=C(C)[N+](=O)[O-])C(=O)N1[Ga]</smiles>

17

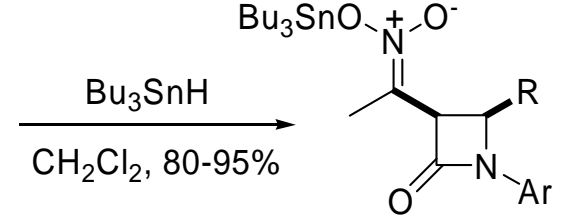

18 $\underset{\text { 1. } \mathrm{O}_{3}, \mathrm{CH}_{2} \mathrm{Cl}_{2},-78^{\circ} \mathrm{C}}{\stackrel{\mathrm{Me}_{2} \mathrm{~S}, 50-78 \%}{\longrightarrow}}$<smiles>[R]C1C(C(C)=O)C(=O)N1[Al]</smiles>

19

$$
\begin{aligned}
& \mathrm{R}=\mathrm{Ph}, \mathrm{Ar}=\mathrm{Ph} \\
& \mathrm{R}=2,5-\mathrm{Me}_{2} \mathrm{C}_{6} \mathrm{H}_{3}, \mathrm{Ar}=\mathrm{Ph} \\
& \mathrm{R}=\mathrm{PhCH}=\mathrm{CHMe}, \mathrm{Ar}=4-\mathrm{MeOC}_{6} \mathrm{H}_{4}
\end{aligned}
$$

\section{Scheme 5}

\section{1,4-Dicarbonyl derivatives}

\subsection{Synthesis of 1,4-dicarbonyls using a conjugate addition-Nef reaction}

As previously stated, conjugate addition of nitroalkanes to enones and enoates provides a rapid entry to the corresponding $\gamma$-nitro carbonyl derivatives that can undergo a Nef reaction giving 1,4-dicarbonyl compounds. This procedure represents one of the most exploited methods to prepare such difunctionalized derivatives that find a number of applications in the synthesis of important target molecules. The Michael addition of nitroalkanes to electron-poor olefins can be realized using basic promoters such as $\mathrm{DBU},{ }^{27} \mathrm{TMG}^{28}{ }^{2}$ triphenylphospine,${ }^{29}$ fluoride salts ${ }^{30}$ and hydroxide (alkoxide) anions. ${ }^{31-34}$ Besides these procedures that work in homogeneous conditions a number of methods using basic catalysts that operate in heterogeneous systems can be employed profitably to carry out a conjugate addition. Basic alumina is a formidable promoter of such nucleophilic additions that can be accomplished even in solvent-less conditions. Reaction of nitroalkanes $\mathbf{1}$ with acrolein $\mathbf{2 0}$ allows a rapid formation of the adduct $\mathbf{2 1}$ that upon oxidative Nef reaction leads to the corresponding 4-oxoalkanoic acid derivative $\mathbf{2 2}$ (Scheme 6). ${ }^{35}$ 
$\mathrm{R}_{\mathrm{O}}^{\mathrm{NO}_{2}}+\overbrace{0^{\circ} \mathrm{C}, 50-56 \%}^{\mathrm{H}}$

1<smiles>[R]C(CCC=O)[N+](=O)[O-]</smiles>

21<smiles>CC(=O)C(=O)O[Mg]</smiles>
$40-80 \%$<smiles>[R]C(=O)CCC(=O)O</smiles>

22

\section{Scheme 6}

A related procedure provides a rapid synthesis of a functionalized cyclopentenone derivative $\mathbf{2 7}$, an advanced intermediate for the preparation of the sesquiterpene cuparene $\mathbf{2 8}$ (Scheme 7). ${ }^{36}$

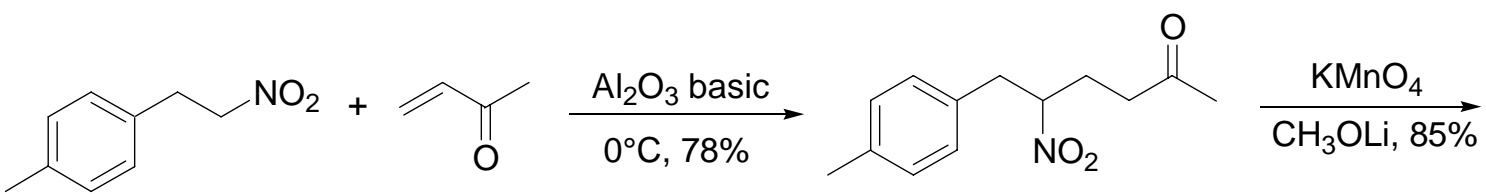

23<smiles>CC(=O)CCC(=O)Cc1ccc(C)cc1</smiles>

26
24
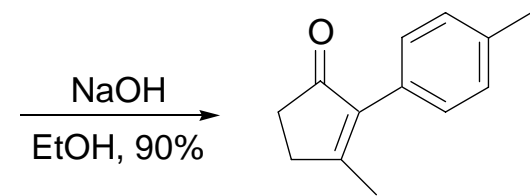

27

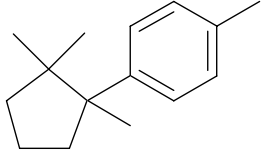

28 cuparene

\section{Scheme 7}

Amberlyst A21 is a macroreticular resin that is particularly efficient in promoting conjugate addition of nitro derivatives $\mathbf{1}$ to acrylate esters 29 (Scheme 8). ${ }^{37}$ The resulting adducts $\mathbf{3 0}$ can be easily converted into the 1,4-dicarbonyl compounds 31 .

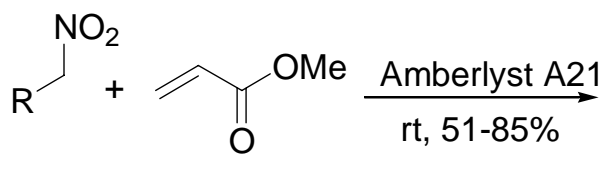

1<smiles>[R]C(CCC(=O)OC)[N+](=O)[O-]</smiles>

30
1. $\mathrm{CH}_{3} \mathrm{OLi}, \mathrm{CH}_{3} \mathrm{OH}, 0^{\circ} \mathrm{C}$

$\frac{\text { 2. } \mathrm{Na}_{2} \mathrm{~B}_{4} \mathrm{O}_{7}, \mathrm{H}_{2} \mathrm{O} \text {, rt }}{\text { 3. } \mathrm{KMnO}_{4}, \mathrm{H}_{2} \mathrm{O}, \mathrm{rt}}$

$60-85 \%$<smiles>[R]C(=O)CCC(=O)OC</smiles>

31

\section{Scheme 8}


Following this strategy, a number of synthetically useful five-membered derivatives 33-35 can be finally prepared from the simple and easily available (Z)-1-nitro-4-heptene 32 (Scheme 9). ${ }^{38}$

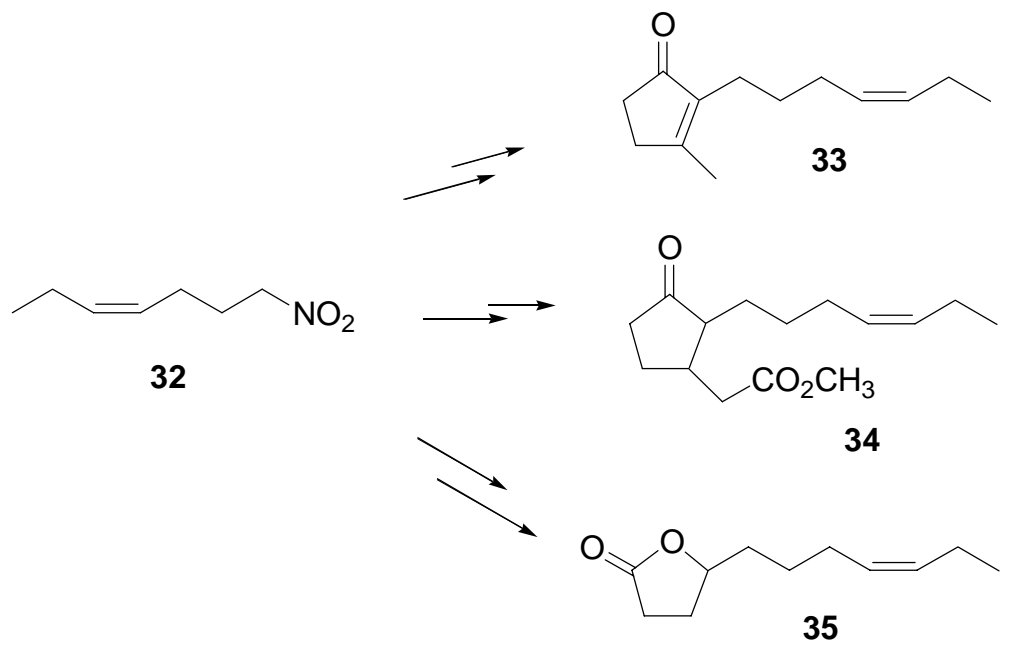

\section{Scheme 9}

Allylrethrone 39 is an important component of an insecticidal pyrethroid and its preparation can be realized in three distinct steps, starting from the nitroalkene $\mathbf{3 6}$ and methyl vinyl ketone (Scheme 10). ${ }^{39}$ The obtained Michael adduct $\mathbf{3 7}$ is converted into the diketone $\mathbf{3 8}$ by a hydrolytic Nef reaction and is then cyclized to allylrethrone 39 under basic conditions. Alternatively, the same process can be realized in a 'one-pot' reaction, using hydrogen peroxide to carry out the nitro to carbonyl conversion.
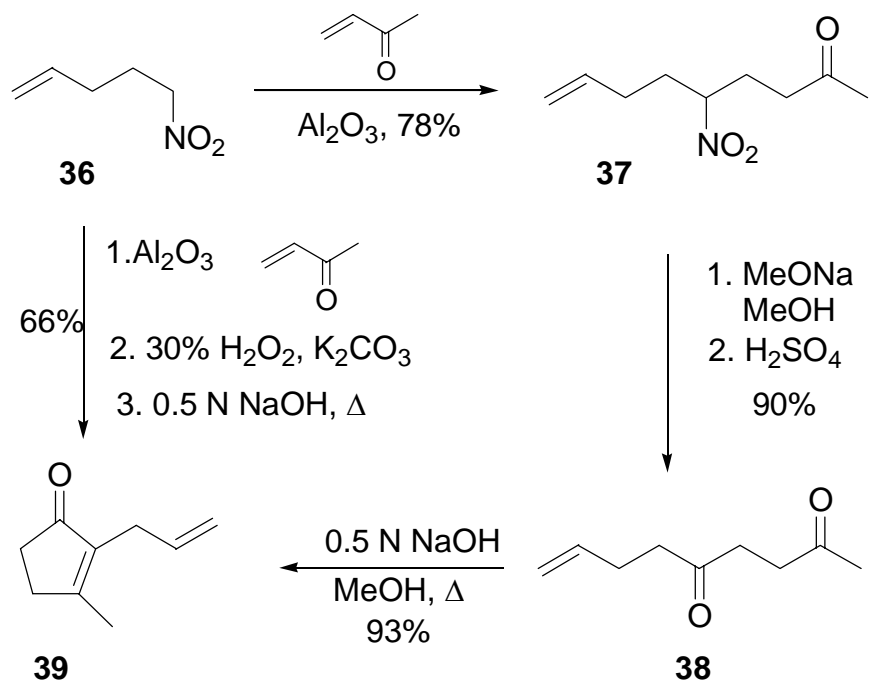

\section{Scheme 10}


The ability of DBU to promote a conjugate addition of nitroalkanes to enones as well as a Nef reaction on secondary nitroalkanes, can be used in a tandem process that permits the direct synthesis of $\gamma$-diketones and $\gamma$-keto esters $\mathbf{4 0}$ (Scheme 11). ${ }^{40}$

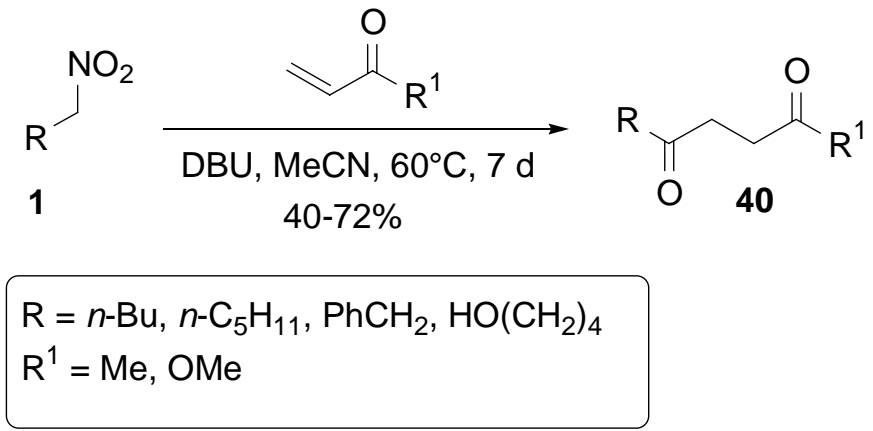

\section{Scheme 11}

The allylic acetates 41 obtained from the Baylis-Hillman procedure, react with nitroalkanes through a conjugate addition-elimination process that leads to the formation of the unsaturated esters $42{ }^{41}$ An hydrolytic nitro to carbonyl conversion on these compounds efficiently affords the (E)-alkylidene-1,4-diketones 43 (Scheme 12).<smiles>[R]C(=O)C(=C)C([R])OC(C)=O</smiles>

41

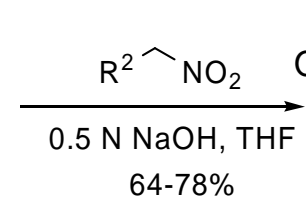

$64-78 \%$

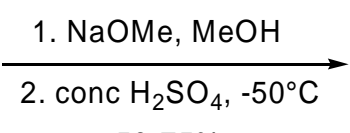

50-75\%

42<smiles>[R]C=C(CC([R])=O)C([R1])=O</smiles>

43

$$
\mathrm{R}=\mathrm{Et}, n-\mathrm{Pr}, i-\mathrm{Pr}, n-\mathrm{C}_{6} \mathrm{H}_{11} \quad \mathrm{R}^{1}=\mathrm{R}^{2}=\mathrm{Me}, \mathrm{Et}
$$

\section{Scheme 12}

A related procedure involves ethyl (2-bromomethyl)acrylate 44 as a Michael acceptor that behaves similarly to the acetates $\mathbf{4 1}$ in the reaction with nitroalkanes, giving the nitro derivatives 45. The nitro group is then transformed into keto ester $\mathbf{4 6}$ by a procedure involving hydrolytic cleavage. A subsequent reduction with $\mathrm{NaBH}_{4}$ in the presence of $\mathrm{Na}_{2} \mathrm{HPO}_{4}$ leads to the corresponding alcohol that by a spontaneous lactonization gives exo-methylene butyrolactones 47 in good overall yields (Scheme 13). ${ }^{42}$ 

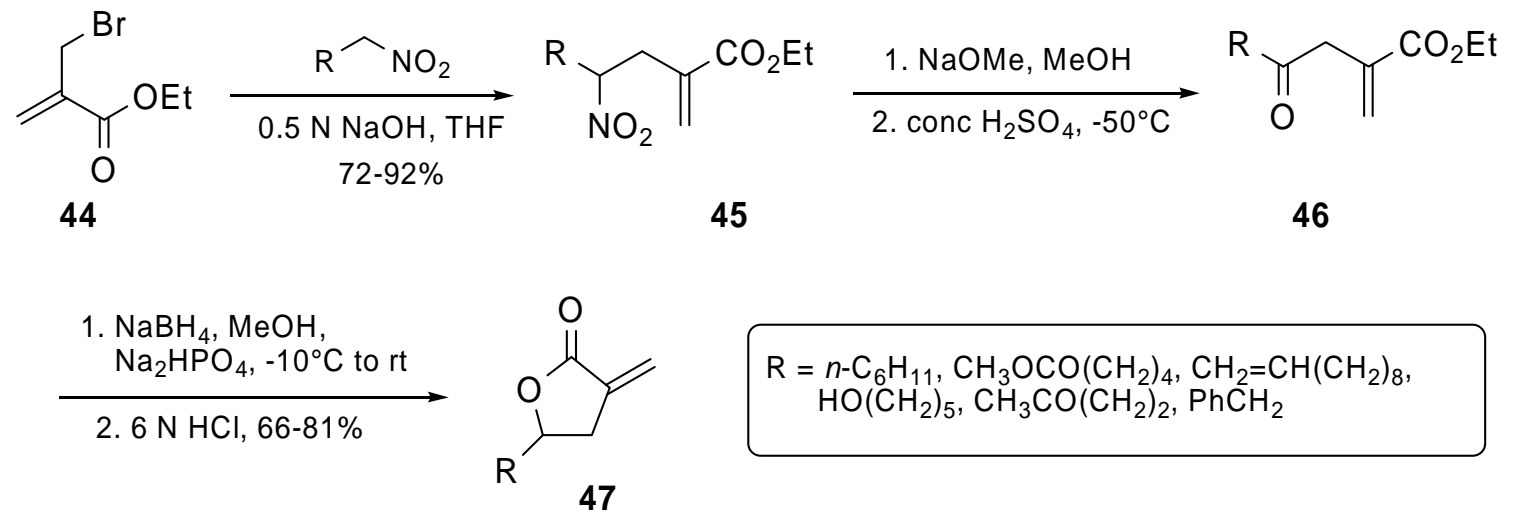

$$
\begin{aligned}
\mathrm{R}= & n-\mathrm{C}_{6} \mathrm{H}_{11}, \mathrm{CH}_{3} \mathrm{OCO}\left(\mathrm{CH}_{2}\right)_{4}, \mathrm{CH}_{2}=\mathrm{CH}\left(\mathrm{CH}_{2}\right)_{8}, \\
& \mathrm{HO}\left(\mathrm{CH}_{2}\right)_{5}, \mathrm{CH}_{3} \mathrm{CO}\left(\mathrm{CH}_{2}\right)_{2}, \mathrm{PhCH}_{2}
\end{aligned}
$$

\section{Scheme 13}

The enedione system is present in many natural products having an interesting biological activity. Conjugate addition of the chiral nitroacetate 48 to methyl propiolate gives the corresponding adduct 49 that is converted into the enedione $\mathbf{5 0}$ by a McMurry reaction involving utilization of $\mathrm{TiCl}_{3}{ }^{43}$ This derivative can be converted into optically active (R,R)-(-)pyrenophorin 51, an antifungal macrolide dilactone (Scheme 14). ${ }^{44}$ A related strategy is also effective for the total synthesis of macrolide $(R)$-patulolide A. ${ }^{45}$

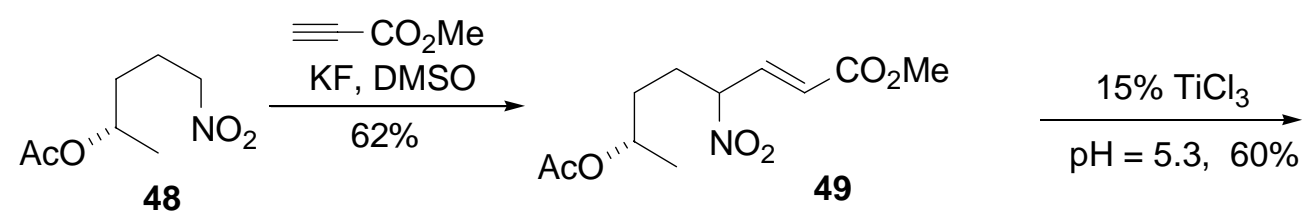<smiles>CC(=O)C=CC(=O)CCC(C)OC(C)=O</smiles>

50
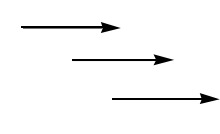<smiles>C/C=C/C(=O)O[C@H](C)CCC(=O)/C=C/C(=O)O[C@H](C)CCC(=O)O</smiles>

$51(-)$-pyrenophorin

\section{Scheme 14}

The cyclopentenone unit is a common motif in a wide array of biologically active substances. The cyclopentenone $\mathbf{5 2}$ reacts with nitromethane giving a trans-substituted nitro derivative that is protected at the carbonyl group as the ketal 53. A Nef reaction on 53 using $\mathrm{TiCl}_{3}$ gives the aldehyde 54 which is converted into the cyclopentenone 55, which shows algicidal properties (Scheme 15). ${ }^{46}$ 


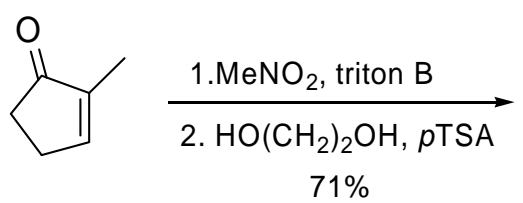

52

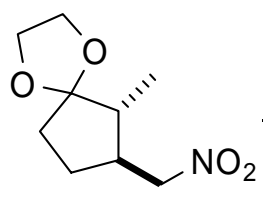

53

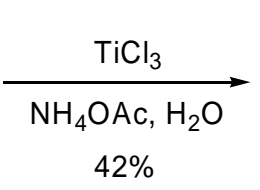

$42 \%$

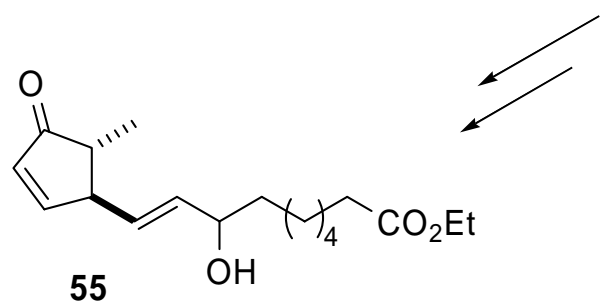

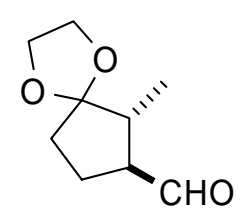

54

\section{Scheme 15}

Primary nitroalkanes can be transformed into aldehydes or carboxylic acids depending on the method used to perform the Nef reaction. The aldehydes 57 can be obtained in good yield by oxidation of the potassium nitronate of primary 4-nitro esters 56 using dimethyldioxirane, a reagent that can be prepared readily by reaction of Oxone ${ }^{\circledR}$ with acetone (Scheme 15). ${ }^{47}$

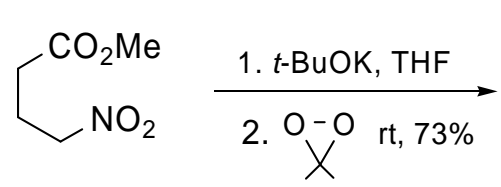

56<smiles>[3H]CCCCCC(=O)OC</smiles>

\section{Scheme 16}

Buffered permanganate solutions $(\mathrm{pH}=11)$ can oxidize primary nitroalkanes such as $\mathbf{5 8}$ into alkanoic acids 59 without affecting other functions such as esters, amides, primary alcohols or acetals (Scheme 17). ${ }^{48}$ This procedure is particularly useful in the preparation of monoesters of 2substituted succinic acids. $^{49}$<smiles>CCOC(CC[N+](=O)[O-])Cc1ccc(Cl)c(Cl)c1</smiles>

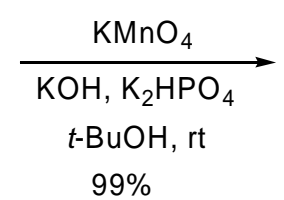<smiles>CCOC(=O)C(CC(=O)O)Cc1ccc(Cl)c(Cl)c1</smiles>

\section{Scheme 17}

Conversely, 2-substituted succinic acids $\mathbf{6 1}$ can be obtained by reaction of nitroalkenes $\mathbf{6 0}$ with Reformatsky reagents obtained from $\alpha$-bromoesters (Scheme 18). ${ }^{50}$ The intermediate adduct 
is readily oxidized using alkaline permanganate solution until the introduced ethyl ester function is fully hydrolyzed.

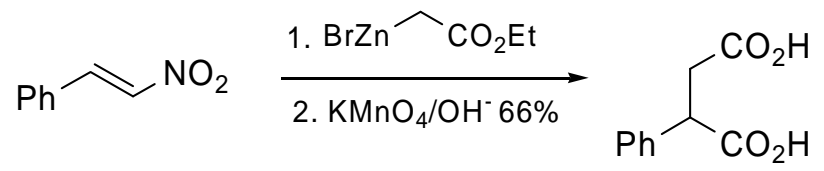

60

61

\section{Scheme 18}

Nitro-olefins can be converted directly into carbonyl derivatives using reductive methods. ${ }^{51,52}$ The chiral nitroenamine 62, obtained from $L$-proline, reacts with the zinc ester enolate $\mathbf{6 3}$, giving the corresponding adduct 64. The chiral nitroolefin lactone 64 can be transformed into the keto lactone $\mathbf{6 5}$ by a tandem nitroolefin reduction-nitronate hydrolysis (Scheme 19). The keto group is cleaved to the parent carboxylic acid $\mathbf{6 6}$ by a haloform reaction and ultimately leads to $(S)$ ethosuximide $67 .{ }^{53}$

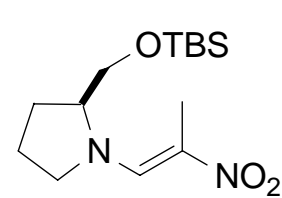

62

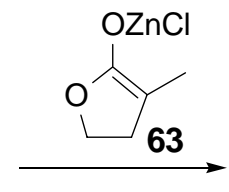

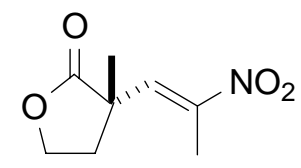

64

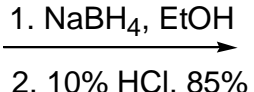

2. $10 \% \mathrm{HCl}, 85 \%$
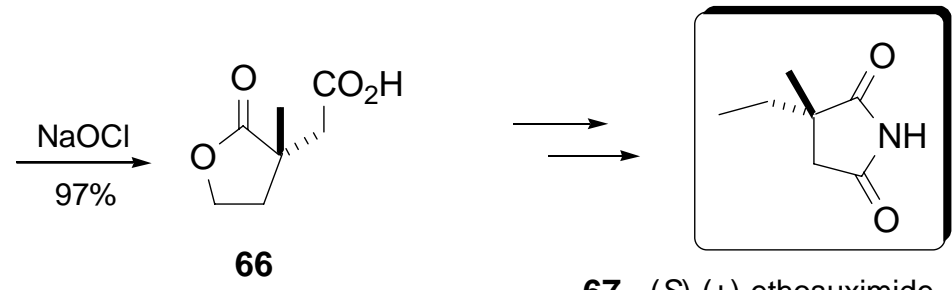

67 (S)-(+)-ethosuximide

\section{Scheme 19}

The same strategy can be used in the total synthesis of the oxindole alkaloid (-)-horsfiline 71. Protection of the indole nitrogen and reduction of nitroolefin 68 affords the nitroalkane 69 that is converted into the carboxylic acid 70 with $\mathrm{NaNO}_{2}$. Further synthetic transformations lead to the preparation of (-)-horsfiline 71 (Scheme 20). ${ }^{54}$ 
<smiles>COc1ccc2c(c1)[C@@](/C=C/[N+](=O)[O-])(CC=C(C)C)C(=O)N2</smiles>

68<smiles>COc1ccc2c(c1)[C@](CC=C(C)C)(CC[N+](=O)[O-])C(=O)N2Cc1ccccc1</smiles>

69<smiles>CNCC1C(=O)N(Cc2ccccc2)c2ccc(OC)cc21</smiles>

71 (-)-horsifiline

\section{Scheme 20}

Propargylation of the nitroalkenes $\mathbf{7 2}$ can be realized using (tributylstannyl)allenes in the presence of $\mathrm{TiCl}_{4}{ }^{55}$ Nitronates $\mathbf{7 3}$ obtained as intermediates can be hydrolyzed to the corresponding ketones $\mathbf{7 4}$ using $3 \mathrm{~N} \mathrm{HCl}$. The obtained $\alpha$-propargylic ketones $\mathbf{7 4}$ are precursors of useful building blocks such as the 1,4-diketones 75 (Scheme 21).

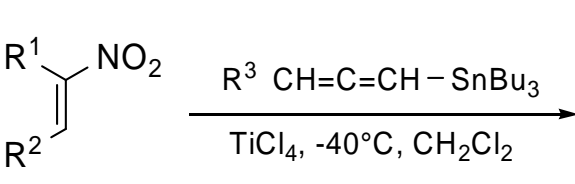

72

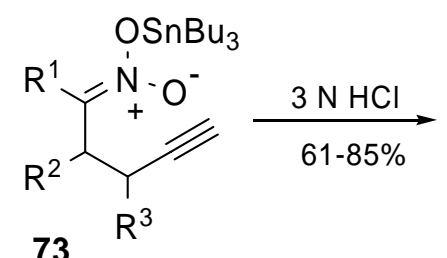

73<smiles>[R]C(=O)C([R])C([R])C#C</smiles>

74

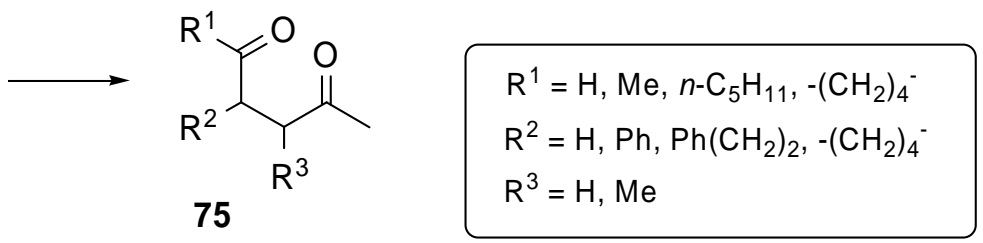

\section{Scheme 21}

The chiral imine $\mathbf{7 6}$ obtained from 2-methylcyclopentanone reacts with 2-nitropropene in a highly regioselective fashion giving a diastereomeric mixture of epimers at $\mathrm{C}-2,77$. The subsequent Nef reaction carried out by acidic hydrolysis of the nitronate anion affords the diketone 78 in $95 \%$ ee (Scheme 22). ${ }^{56}$ 
<smiles>CC1CCCC1=NC(C)c1ccccc1</smiles>

76

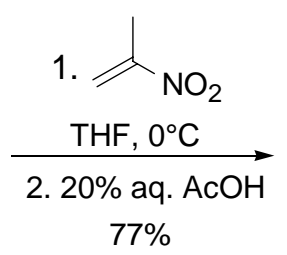

$77 \%$

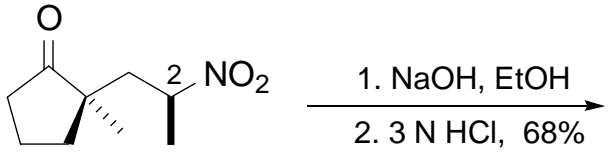

$77(d r=9: 1)$

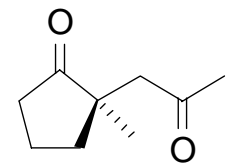

78 (95\% ee)

\section{Scheme 22}

The high reactivity of 2-nitropropene allows its reaction even with the silyl enol ether $\mathbf{7 9}$ in the presence of $\mathrm{SnCl}_{4}$ to give the corresponding adduct, which is converted into diketone $\mathbf{8 0}$ using Oxone ${ }^{\circledR}$ (Scheme 23). ${ }^{57}$ This compound is then transformed by an intramolecular aldol condensation into the bicycloketone $\mathbf{8 1}$ that is an important intermediate for the synthesis of polyquinane derivatives.

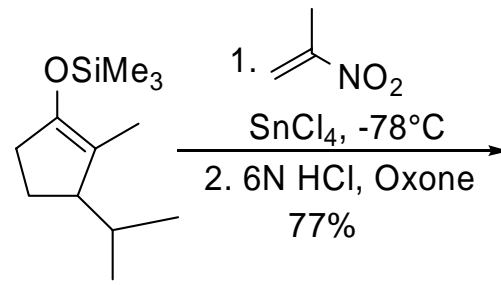

79

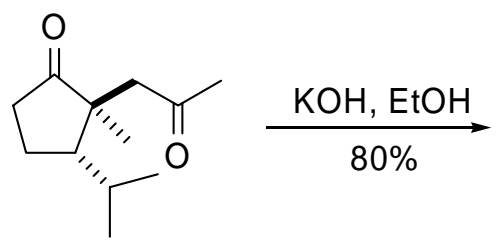

80

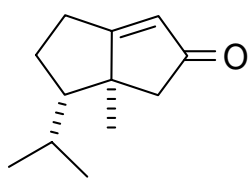

81

\section{Scheme 23}

\subsection{Synthesis of 1,4-dicarbonyls using a nitroaldol and alkylation reactions}

The products obtained from a nitroaldol reaction are usually 1,2-nitro alcohols, unless these derivatives undergo elimination of water under the reaction conditions to afford the corresponding nitroalkenes. ${ }^{58}$ At this point, the introduction of a carbonyl group in the molecular framework can be realized by oxidation of the hydroxy group of the nitro alcohol, followed by a reductive denitration in order to eliminate the nitro group. Alternatively, the nitro group in the nitroalkene moiety can be converted directly into a carbonyl group by the usual Nef reaction. Condensation of the nitro dioxolane $\mathbf{8 2}$ with aldehydes $\mathbf{8 3}$ affords the corresponding nitro alcohols that can be oxidized in a 'one pot' procedure to the parent nitro ketones 84 (Scheme 24). ${ }^{59,60}$ This derivative can be denitrated using a procedure that involves its conversion into a tosylhydrazone 85 followed by reduction with $\mathrm{LiAlH}_{4} \cdot{ }^{61}$ Cleavage of the protecting groups of the obtained compounds $\mathbf{8 6}$ in acidic conditions affords the 1,4-diketones 87 in satisfactory overall yield. 


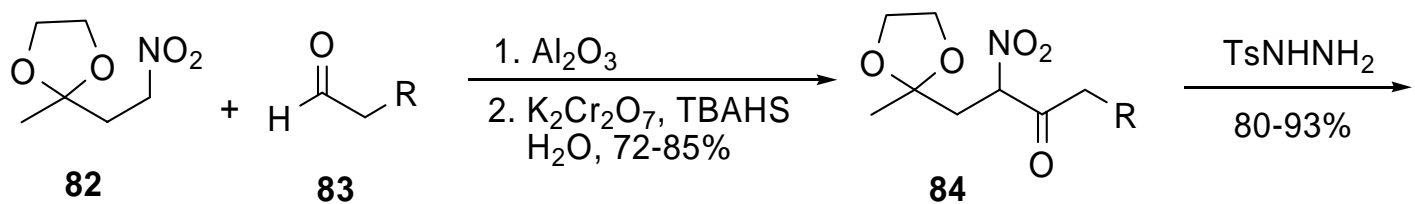<smiles>[R]CC(=[NH2+])C(CC1(C)OCCO1)[N+](=O)[O-]</smiles>

85<smiles>[R]CC(=O)CCC(C)=O</smiles>

87

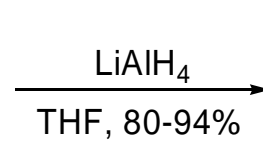

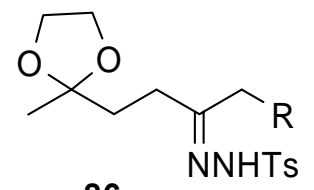

86

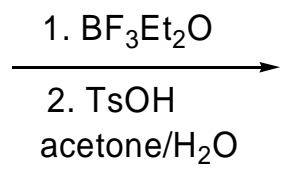

$68-84 \%$

$$
\mathrm{R}=\mathrm{H}, \mathrm{Bn}, n-\mathrm{C}_{5} \mathrm{H}_{11},(Z)-\mathrm{CH}_{2} \mathrm{CH}=\mathrm{CHCH}_{2} \mathrm{CH}_{3}
$$

\section{Scheme 24}

The ability of the nitro group to act as a good leaving group in elimination reactions can be used for the preparation of $(E)$-enediones that are valuable intermediates for the synthesis of biologically active compounds. (E)-Non-3-ene-2,5-dione 92 is the main component of the volatile compounds obtained from the cephalic secretion of workers of Trigona tataira. Nitroaldol reaction between aldehyde $\mathbf{8 8}$ and the nitro alcohol $\mathbf{8 9}$ affords the corresponding nitro diol 90 that upon oxidation under phase-transfer conditions of the hydroxy groups, leads to the nitro diketone 91 (Scheme 25). ${ }^{62,63}$ Base- assisted elimination of nitrous acid from compound 91 allows the total synthesis of enedione 92 in $70 \%$ overall yield.
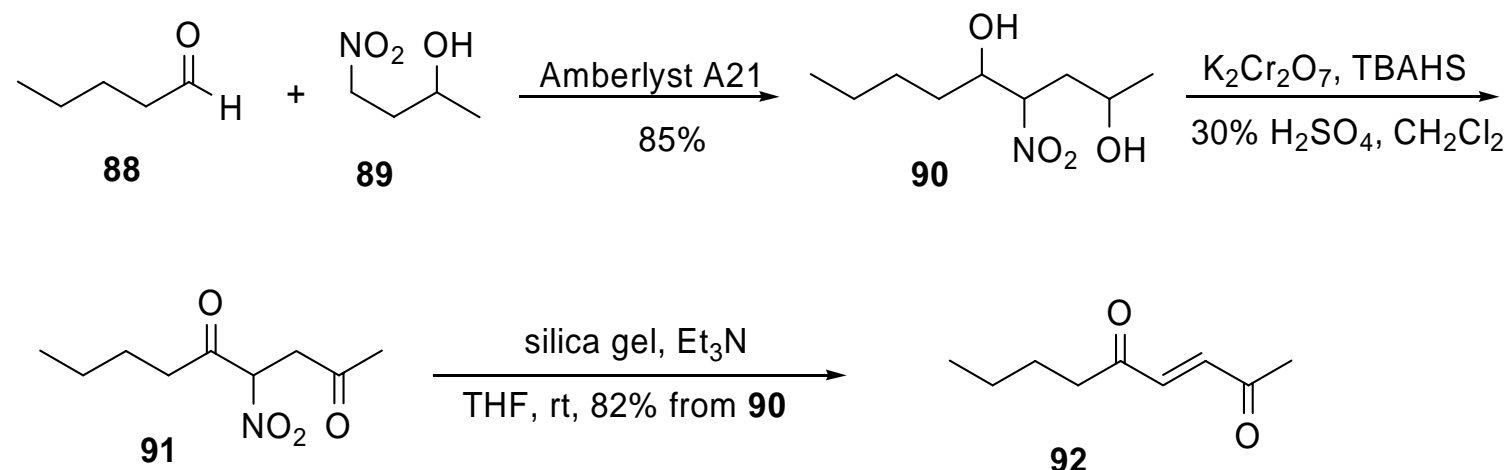<smiles>CCCCC(=O)/C=C/C(C)=O</smiles>

\section{Scheme 25}

As previously stated, nitroalkenes such as 94 can be obtained directly by a nitroaldolelimination that can be carried out in a 'one pot' process from nitro derivative 93 and various aldehydes 83 (Scheme 26). ${ }^{64}$ Reduction of the nitroalkene double bond using $\mathrm{NaBH}_{4}$ produces an 
intermediate sodium nitronate that can be oxidized using hydrogen peroxide in basic conditions to give ketone 95. The second carbonyl unit can be introduced by a Wacker oxidation using molecular oxygen in the presence of catalytic amounts of $\mathrm{PdCl}_{2}$ and $\mathrm{CuCl}_{2}$ thus affording the 1,4-diketone 96.

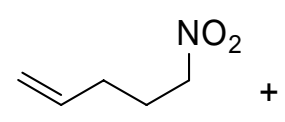

93<smiles>[R]CCC(=O)CCC=C</smiles>

95

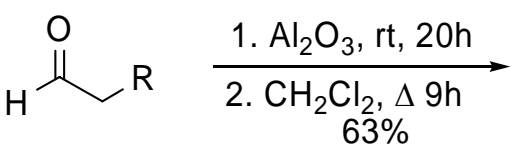

83

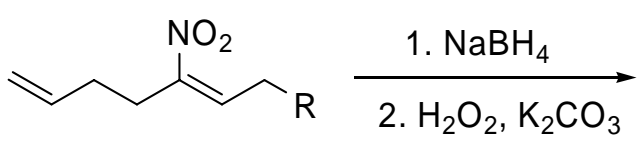

94 $58 \%$<smiles>[R]CCC(=O)CCC(C)=O</smiles>

96

\section{Scheme 26}

Although C-alkylation of nitronate anions is a less common process than the nitroaldol condensation, it can be particularly effective in intramolecular reactions. Ring-closure, of the nitroiodide 97, using $\mathrm{NaH}$ to generate the nitronate anion, affords the nitrocyclohexane 98 that is converted into the cyclohexanone 99 using $\mathrm{TiCl}_{3}$. (Scheme 27). ${ }^{65,66}$ This intermediate can be transformed into $(+)$-podocarpic acid $\mathbf{1 0 0}$ in a few steps.<smiles>COC(=O)CCCCI</smiles>

97<smiles>COC(=O)[C@H]1CCC[C@@H]([N+](=O)[O-])[C@H]1CC[AlH2]</smiles>

98<smiles>CC12CCC[C@@](C)(C(=O)O)[C@H]1CCc1ccc(O)cc12</smiles>

100 (+)-podocarpic acid

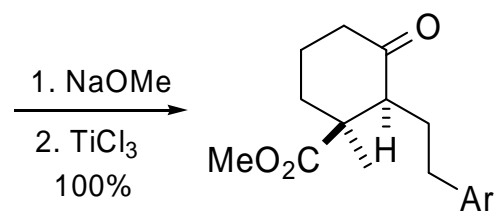

99

\section{Scheme 27}




\section{1,5-Dicarbonyl and 1,6-dicarbonyl derivatives}

2-Nitro- ketones form the corresponding nitronate anion in weakly basic conditions, as a result of the additional activating effect of the carbonyl group. ${ }^{67,68}$ The nitro group in 2-nitro ketones is particularly prone to undergoing a radical-induced denitration using $\mathrm{Bu}_{3} \mathrm{SnH}$, giving rise to the corresponding reduction product. ${ }^{69}$ Michael addition of the $\alpha$-nitro ketones $\mathbf{1 0 1}$ with enones affords the nitro diketones $\mathbf{1 0 2}$ that upon denitration give the 1,5-dicarbonyl derivatives $\mathbf{1 0 3}$, usually in good yield (Scheme 28). ${ }^{70,71}$

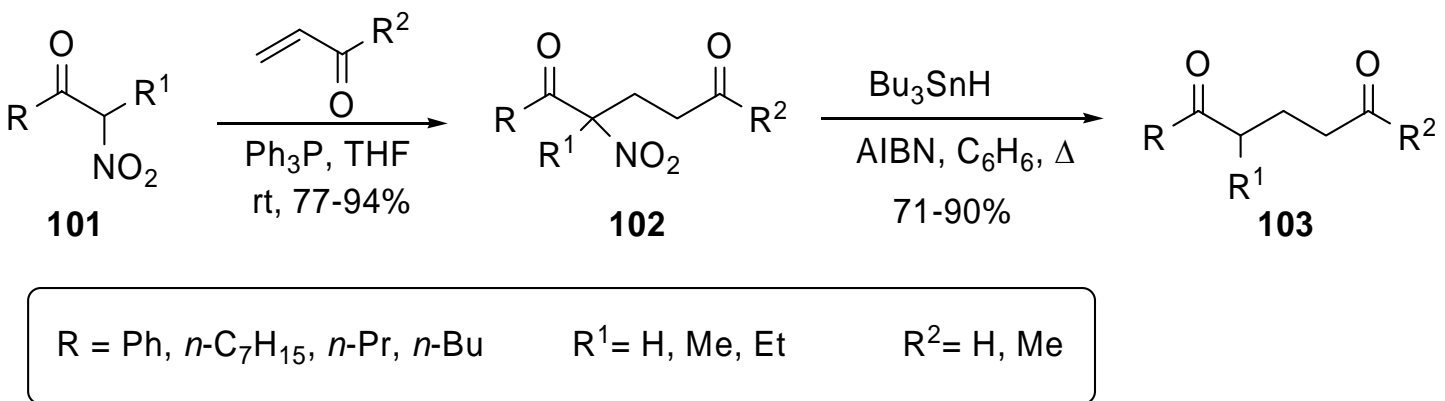

\section{Scheme 28}

The conjugate addition of 2-nitro ketones is usually carried out in basic conditions, ${ }^{72}$ but the easy enolization of these compounds offers the opportunity to realize this process even under solid acidic catalysis by $\mathrm{SiO}_{2}{ }^{73}$

The nitroaldol condensation can be used to prepare 1,5-dicarbonyl derivatives from 1,4homologues. Reaction of aldehyde 104 with 1-nitrododecane followed by dehydration gives the nitroalkene 105 (Scheme 29). ${ }^{74}$ The nitroalkene 105 is then converted into the ketoester derivative 106, a pivotal intermediate for the synthesis of the pancreatic lipase inhibitor tetrahydrolipstatin, 107. 

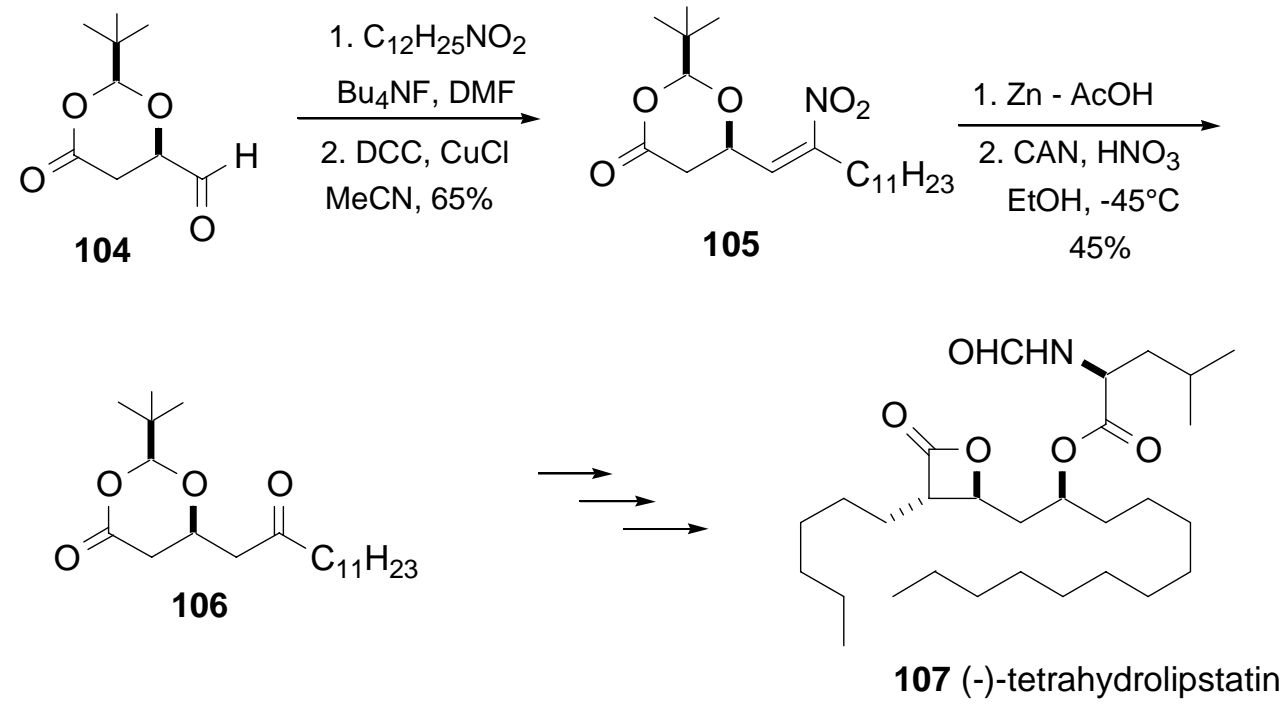

\section{Scheme 29}

Organozinc reagents bearing a terminal ester function can be profitably used for the preparation of the 1,6-dicarbonyl compound 109 by reaction with nitroalkenes 108 followed by a Nef reaction (Scheme 30). ${ }^{75}$

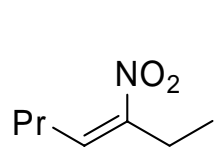

108

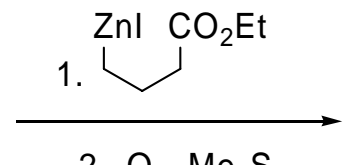

2. $\mathrm{O}_{3}, \mathrm{Me}_{2} \mathrm{~S}$

$85 \%$<smiles>CCCC(CCCC(=O)CC)C(=O)CC</smiles>

109

\section{Scheme 30}

The nitroalkene $\mathbf{1 1 0}$ is a common product obtained by a nitroaldol-elimination reaction that under a reductive Nef reaction gives the keto ester 111 in satisfactory yield (Scheme 31). ${ }^{76}$ The alkyl appendage linked to the keto group can be suitably changed using different aldehydes during the nitroaldol reaction.

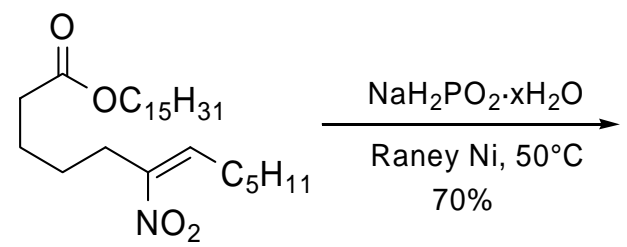

110

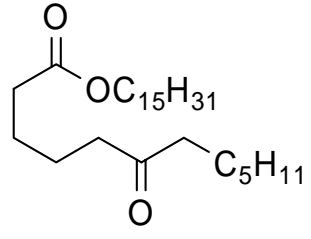

111

\section{Scheme 31}


A retro- nitroaldol reaction on the nitrocyclohexanol 112 gives the open-chain nitro ketone 113 that undergoes a tandem Michael addition-Nef reaction upon reaction with $\mathrm{NaOMe}$, followed by quick acidification with $\mathrm{H}_{2} \mathrm{SO}_{4}$ to give the keto ester 114. This derivative is a key intermediate in the synthesis of optically active $(R)$ - $\alpha$-lipoic acid 115 (Scheme 32$){ }^{77}$

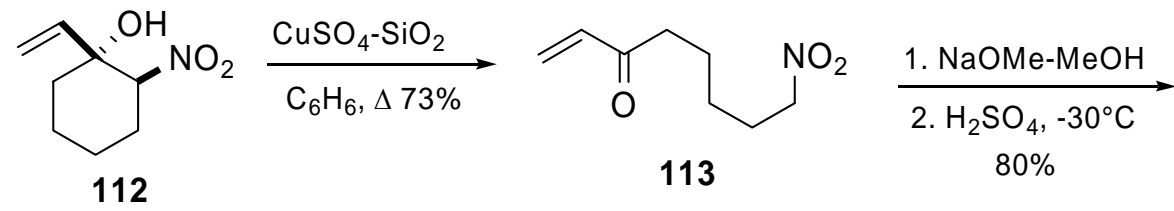

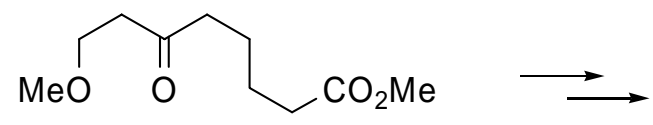

114

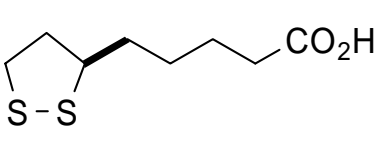

$115(R)-\alpha$-lipoic acid

\section{Scheme 32}

The dianion of the $\beta$-enamino ketone 117, prepared from 116, reacts with nitrostyrene 118 at low temperature giving the corresponding nitronate adduct 119. Upon quenching of this intermediate at $0^{\circ} \mathrm{C}$ with $2 \mathrm{~N} \mathrm{H}_{2} \mathrm{SO}_{4}$, the initially formed aldehyde, 120, undergoes a rapid cyclization to the dihydropyrrole 121 in $60 \%$ overall yield (Scheme 33 ). ${ }^{78}$

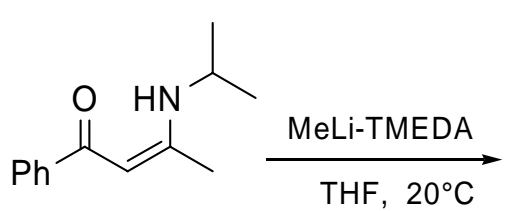

116<smiles>C=C(/C=C(\O)c1ccccc1)/N=C(\[Te])C(C)C</smiles>

117

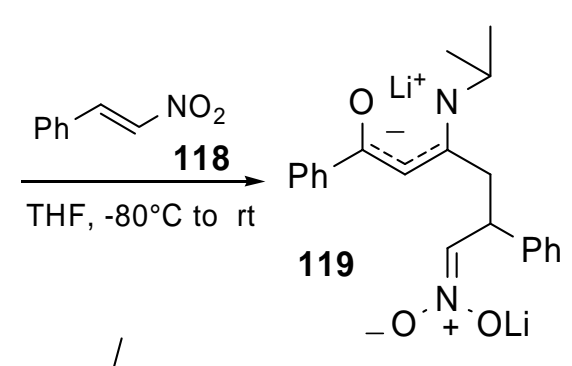

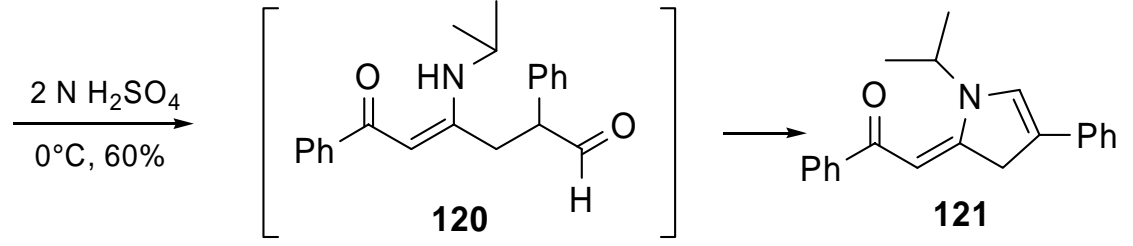

\section{Scheme 33}

\section{5. $\alpha, \omega$-Dicarbonyl derivatives by ring cleavage of 2-nitrocycloalkanones}

Retro-Claisen condensation of 2-nitrocycloalkanones represents a straightforward route to functionalized terminal nitro esters. ${ }^{79}$ Coupling the ring cleavage of the cycle with a Nef reaction allows a direct preparation of $\alpha, \omega$-diester derivatives having an alkyl chain length that depends 
on the ring size of the starting 2-nitrocycloalkanone. Potassium persulfate in methanol in the presence of sulfuric acid is able to cleave the 2-nitrocycloalkanones, 122, giving the corresponding $\alpha, \omega$-dicarboxylic acid methyl esters 123 (Scheme 34). ${ }^{80}$ The utilization of hydrogen peroxide in the presence of potassium carbonate starting from compounds $\mathbf{1 2 2}$ allows the preparation of $\alpha, \omega$-dicarboxylic acids and keto acids. ${ }^{81}$<smiles>O=C1CCCCC1[N+](=O)[O-]</smiles>

122

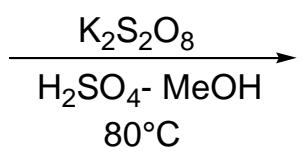

$80^{\circ} \mathrm{C}$

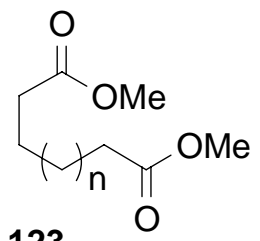

123

n = 0 (92\%); 1 (93\%); 2 (90\%); 3 (86\%); 4 (80\%);

5 (81\%); 6 (85\%); 7 (88\%); 10 (78\%)

\section{Scheme 34}

$\alpha, \omega$-Dicarboxylic acids or their methyl monoesters such as $\mathbf{1 2 5}$ can be obtained regioselectively starting from 2-nitrocycloalkanones 124 using Oxone ${ }^{\circledR}$ in buffered conditions. The carbon atom originally bearing the nitro group is always converted into a free acid function (Scheme 35). ${ }^{82}$<smiles>COc1cccc2c1CCC([N+](=O)[O-])C2=O</smiles>

124

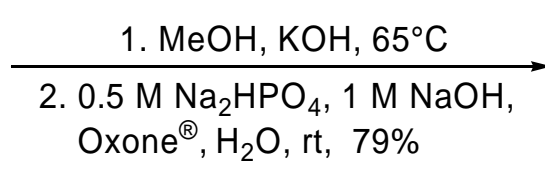

Oxone ${ }^{\circledR}, \mathrm{H}_{2} \mathrm{O}, \mathrm{rt}, 79 \%$<smiles>COC(=O)c1cccc(OC)c1CCC(=O)O</smiles>

125

\section{Scheme 35}

\section{Tunable syntheses of $1, n$-dicarbonyl derivatives}

Nitro ketones, protected at the carbonyl group as cyclic ketals, can be used as masked 1,n dicarbonyl synthons $(\mathrm{n}=3-5)$ for the preparation of various difunctionalized systems. Condensation of the nitro ketals $\mathbf{1 2 6}$ with aldehydes $\mathbf{1 2 7}$ followed by in situ elimination affords the nitroalkenes 128. Such unsaturated derivatives are transformed into ketones 129 and, upon cleavage of the dioxolane ring, are finally converted into 1,n-diketones $\mathbf{1 3 0}$ (Scheme 36). ${ }^{83}$ 


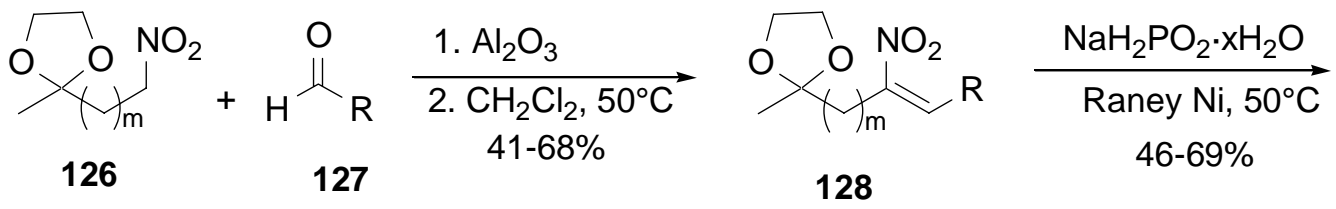

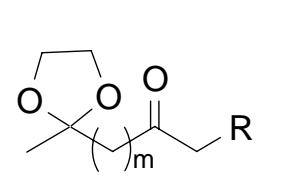

129

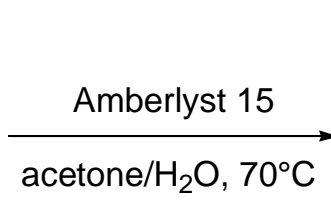
acetone $/ \mathrm{H}_{2} \mathrm{O}, 70^{\circ} \mathrm{C}$

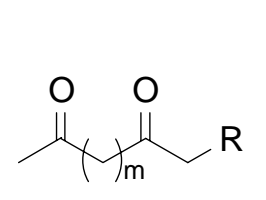

130

\begin{tabular}{|llc|}
\hline $\mathrm{m}$ & $\mathrm{R}$ & $\mathbf{1 3 0}$ yield(\%) \\
\hline 1 & $n-\mathrm{C}_{10} \mathrm{H}_{21}$ & 90 \\
1 & $\mathrm{Ph}\left(\mathrm{CH}_{2}\right)_{2}$ & 87 \\
2 & $n-\mathrm{C}_{5} \mathrm{H}_{11}$ & 97 \\
2 & $c-\mathrm{C}_{6} \mathrm{H}_{11}$ & 95 \\
3 & $n-\mathrm{C}_{5} \mathrm{H}_{11}$ & 90 \\
\hline
\end{tabular}

\section{Scheme 36}

A related procedure using different nitro esters $\mathbf{1 3 1}$ allows an efficient synthesis of [n+2]keto esters $132(n=1-3)($ Scheme 37$) .{ }^{84}$

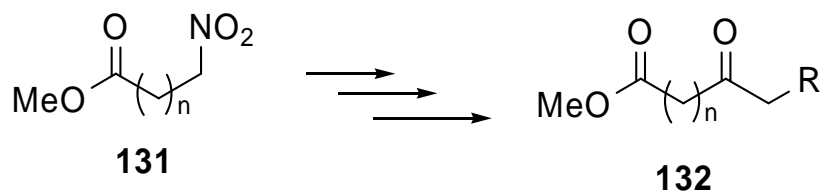

\section{Scheme 37}

Methyl 8-nitrooctanoate $\mathbf{1 3 3}$ can be used as starting material for the preparation of (E)-9oxo-2-decenoic acid 137, an important sex attractant of the queen bee, also implicated as a pheromone of termites (Scheme 38). ${ }^{85}$ The overall procedure involves a nitroaldol reaction of 133 with acetaldehyde to give nitro alcohol $\mathbf{1 3 4}$ that is oxidized to the corresponding 2-nitro ketone 135. Reductive denitration of compound $\mathbf{1 3 5}$ gives the 9-ketoester $\mathbf{1 3 6}$ that is subsequently converted into acid $\mathbf{1 3 7}$ in few steps. 
<smiles>COC(=O)CCCCCC[N+](=O)[O-]</smiles><smiles>COC(=O)CCCCCC(CCC(=O)[N+](=O)[O-])[N+](=O)[O-]</smiles>

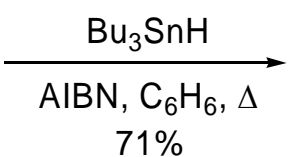

135<smiles>CC(=O)CCCCC/C=C/C(=O)O</smiles><smiles>COC(=O)CCCCCCC(C)=O</smiles>

\section{Scheme 38}

Conjugate addition of 2-nitrocycloalkanones $\mathbf{1 2 2}$ to acrolein gives the corresponding aldehydes 138 that upon reduction with $\mathrm{NaBH}_{4}$ afford alcohols 139 (Scheme 39). ${ }^{86}$ An intramolecular retro-Claisen cleavage promoted by $\mathrm{NaH}$ allows the preparation of macrolactones 140 that are converted into keto esters 141 by oxidative Nef reaction using cerium ammonium nitrate $(\mathrm{CAN})$.<smiles>O=C1CCCCC1[N+](=O)[O-]</smiles><smiles>C/C=C\COCCOCCO</smiles>
$122 \mathrm{n}=1,2,3,7$<smiles>O=CCCC1([N+](=O)[O-])CCCCC1=O</smiles>

138

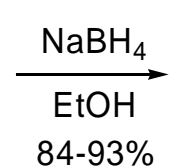

$84-93 \%$

139<smiles>C[Si](C)(C)O[Na]</smiles>

140

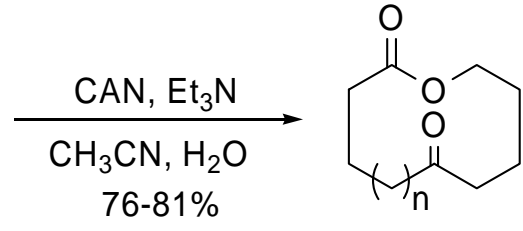

141

\section{Scheme 39}




\section{Tricarbonyl derivatives}

The strategies described above for the preparation of 1,n-dicarbonyl derivatives are often amenable for the synthesis of compounds containing three or more carbonyl groups. Double conjugate addition of nitromethane to enones $\mathbf{1 4 2}$ followed by in situ Nef reaction of the resulting adducts provides a straightforward entry to 1,4,7-triketo derivatives 143 (Scheme 40). ${ }^{87}$

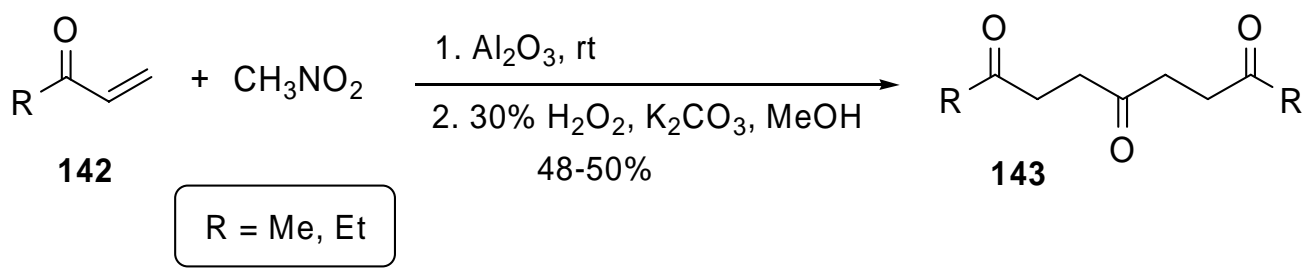

\section{Scheme 40}

Reaction of the $\gamma$-nitro ketone 144 with cyclic $\beta$-ketoesters 145 directly affords bicyclic compounds $\mathbf{1 4 6}$ through a conjugate addition-aldol condensation reaction (Scheme 41). ${ }^{88,89}$ These derivatives are important precursors of the germination stimulant strigol and its synthetic analogs.

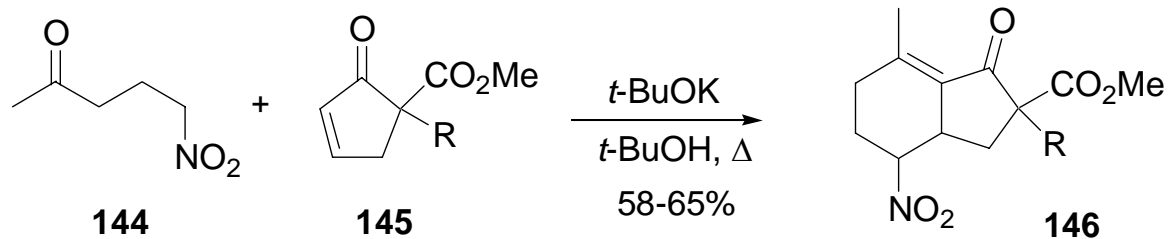

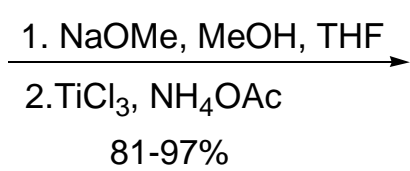

$81-97 \%$<smiles>[R]C1(C(C)=O)CC2C(=O)CCC(C)=C2C1=O</smiles>

147

\section{Scheme 41}

The 2-nitrocycloalkanones $\mathbf{1 2 2}$ react with enones in the presence of triphenylphospine to give the Michael adducts $\mathbf{1 4 8}$ that, by the simple addition of a methanolic solution of $\mathrm{KOH}$, are cleaved to the corresponding open-chain nitronate anions 149 (Scheme 42). ${ }^{90,91}$ These intermediates undergo a Nef reaction using $\mathrm{KMnO}_{4}$ to afford the triketo derivatives 150. This overall transformation is realized in a 'one-pot' procedure and avoids the isolation of any intermediates. 

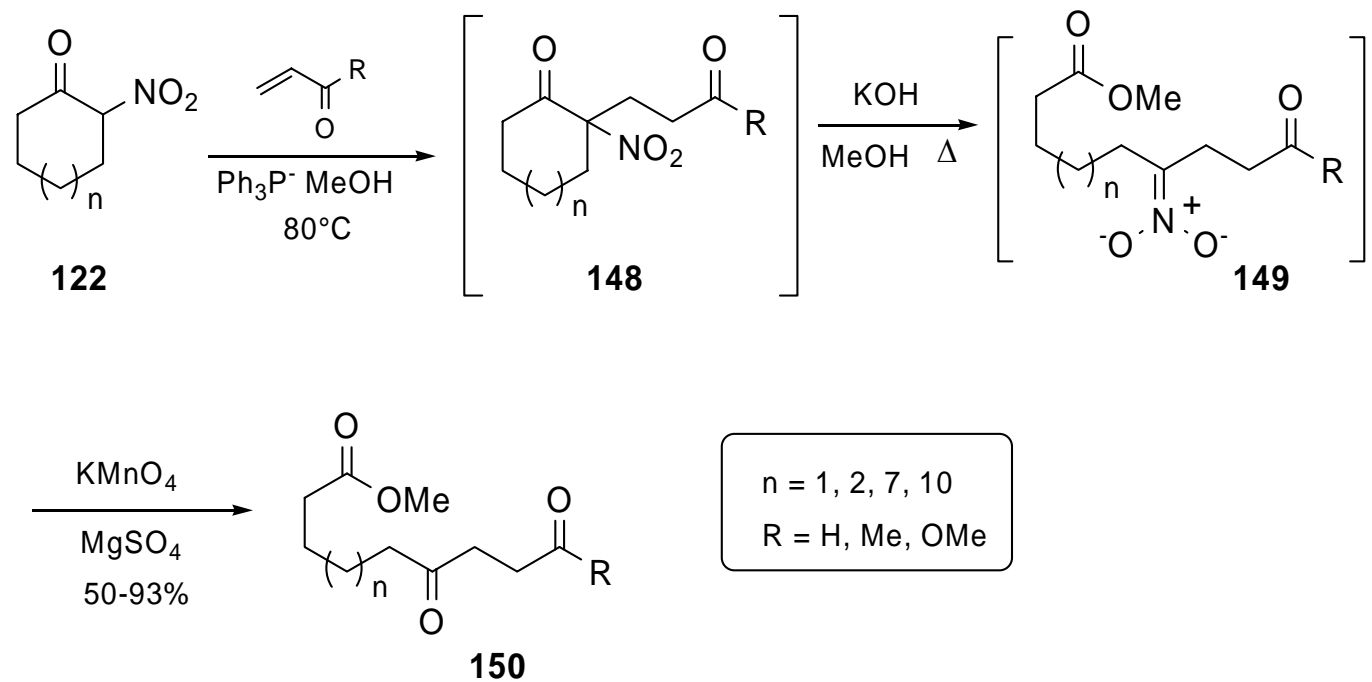

\section{Scheme 42}

An unusual behavior can be observed upon reaction of the nitroalkanes 1 with dimethyl citraconate 151 in the presence of DBU. As observed by ${ }^{1} \mathrm{H}$ - NMR analysis, in the presence of DBU there is an equilibrium between 151 and its regioisomer 152 that is probably more reactive towards Michael addition with nitroalkanes. The adducts 153 formed by the usual conjugate addition are therefore subsequently transformed into the keto diesters 154 by a Nef reaction (Scheme 43). ${ }^{92}$
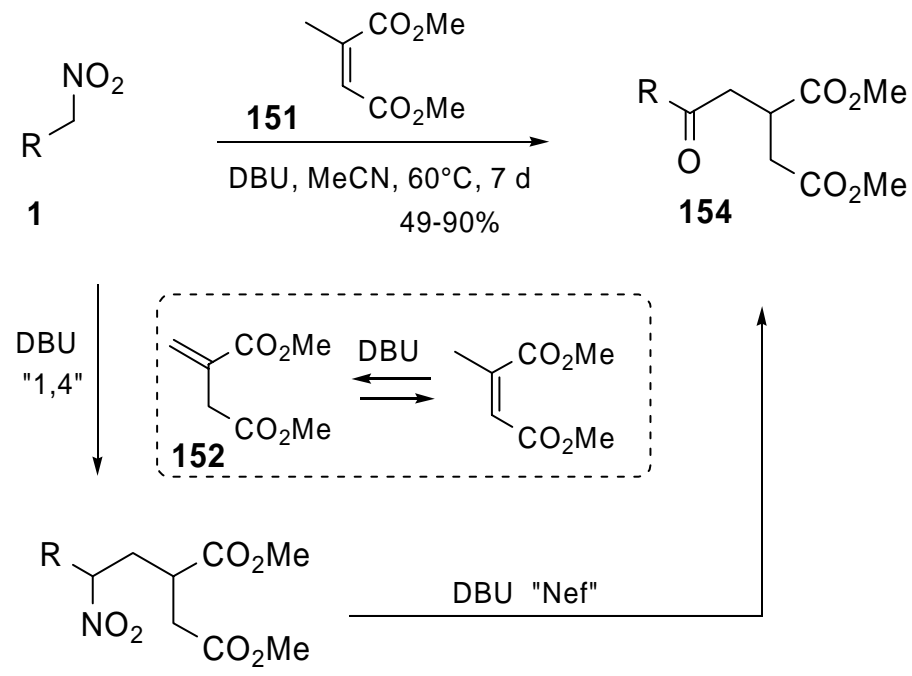

153

$\mathrm{R}=\mathrm{Me}, \mathrm{n}-\mathrm{C}_{6} \mathrm{H}_{11},\left(\mathrm{CH}_{3}\right)_{2} \mathrm{CHCH}_{2}, \mathrm{CH}_{2}=\mathrm{CH}\left(\mathrm{CH}_{2}\right)_{8}$, $\mathrm{HO}\left(\mathrm{CH}_{2}\right)_{5}, \mathrm{CH}_{3} \mathrm{CO}\left(\mathrm{CH}_{2}\right)_{2}, \mathrm{PhCH}_{2}$

\section{Scheme 43}


Stable-isotope- labeled $\mathrm{L}$-glutamic acid can be prepared from ${ }^{13} \mathrm{C}$-enriched compounds, following a strategy involving the conjugate addition of ethyl nitroacetate $\mathbf{1 5 5}$ to ethyl acrylate. Oxidative Nef conversion of the 2-nitroglutarate 156 to diethyl 2-oxoglutarate, and ester hydrolysis, gives 2-oxoglutaric acid 157. This diacid is transformed into L-glutamic acid 158 using the commercially available enzyme glutamic dehydrogenase, in the presence of ammonium ions (Scheme 44). ${ }^{93}$<smiles>CCOC(=O)C[N+](=O)[O-]</smiles>

155<smiles>O=C(O)CCC(=O)C(=O)O</smiles>

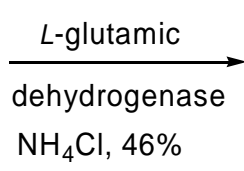

$\mathrm{NH}_{4} \mathrm{Cl}, 46 \%$<smiles>CCOC(=O)CCC(C(=O)OCC)[N+](=O)[O-]</smiles>

156

$67 \%$<smiles>N[C@@H](CCC(=O)O)C(=O)O</smiles>

\section{Scheme 44}

\section{Conclusions}

Many synthetic approaches directed to the preparation of dicarbonyl derivatives enjoy the utilization of nitroalkanes as useful reagents for building up the alkyl framework. Conjugate addition to electron-poor alkenes and nitroaldol condensation are the most exploited procedures to attain this important result. The ability of the nitro group to be converted into a carbonyl group represents the key step of most of the procedures devoted to the preparation of 1,4-dicarbonyl derivatives. This synthetic opportunity is not limited to simple nitroalkanes but can be extended to nitroalkenes, easily obtained by dehydration of the corresponding nitro alcohols. In functionalized reagents such as 2-nitro ketones, the nitro group in the final adduct can be easily removed by reductive denitration or elimination as nitrous acid allowing the preparation of dicarbonyl compounds having a variable distance between the carbonyl groups. All these procedures involving the utilization of nitroalkanes as pivotal reagents for the synthesis of dicarbonyl compounds make the use of these nitrogenated derivatives a formidable tool in organic chemistry. 


\section{Acknowledgments}

The authors are greatly indebted to their co-workers whose names are cited in the references, for their enthusiasm and dedication. Financial support has been granted by M.I.U.R. (COFIN "Sintesi e reattività-attività di composti insaturi funzionalizzati) and the University of Camerino.

\section{References}

1. Simon, C.; Constantieux, T.; Rodriguez, J. Eur. J. Org. Chem. 2004, 4957.

2. Pätzel, M.; Liebscher, J. Synthesis 1995, 879.

3. Eicher, T.; Hauptmann, S. The Chemistry of Heterocycles, Georg Thieme Verlag: New York 1995.

4. Dean, F. M. Adv. Heterocycl. Chem. 1982, 30, 172.

5. Sundberg, R. J. In Comprehensive Heterocyclic Chemistry, Vol. 4, Katritzky A. R., Rees, C. W. Eds.; Pergamon: Oxford, 1984; p329.

6. Ellison, R. A. Synthesis 1973, 397

7. Ho, T. L. Synth. Commun. 1974, 4, 265

8. Stetter, H.; Kuhlmann, H. Org. React. 1991, 40, 407.

9. Heat, R. J.; Rock, C. O. Nat. Prod. Rep. 2002, 19, 581

10. Davis, B. R.; Garratt, P. J. In Comprehensive Organic Synthesis, Vol. 2, Trost, B. M.; Fleming, I.; Heathcock, C. H. Eds. Pergamon: Oxford, 1991, p795.

11. Perlmutter, P. Conjugate Addition Reactions in Organic Synthesis Pergamon: Oxford, 1992.

12. Rosini, G.; Ballini, R. Synthesis 1988, 833.

13. Nitro Compounds Recent Advances in Synthesis and Chemistry, Feuer, H.; Nielsen, A.T. Eds.; VCH: Weinheim, 1990.

14. Ono, N. The Nitro Group in Organic Synthesis, Wiley-VCH: New York, 2001.

15. The Chemistry of Amino, Nitroso, Nitro and Related Groups, Patai, S., Ed.; Wiley: Chichester, 1996.

16. Adams, J. P. J. Chem. Soc., Perkin Trans. 1 2002, 2586.

17. Seebach, D.; Lehr, F. Angew. Chem. Int., Ed. Engl. 1976, 15, 505.

18. Rosini, G. In Comprehensive Organic Synthesis, Trost, B. M. Ed.; Pergamon: Oxford, 1991; Vol. 2, p.321.

19. Luzzio, F. A. Tetrahedron 2001, 57, 915.

20. Ballini, R.; Bosica, G.; Fiorini, D.; Palmieri, A.; Petrini, M. Chem. Rev. 2005, 105, 933.

21. Ballini, R.; Petrini, M. Tetrahedron 2004, 60, 1017.

22. Pinnick, H. W. Org. React. 1990, 38, 655.

23. Nikalje, M. D.; Sayyed Ali, I.; Dewkar, G. K.; Sudalai, A. Tetrahedron Lett. 2000, 41, 959.

24. Vankar, Y. D.; Shah, K.; Bawa, A.; Singh, S. P. Tetrahedron 1991, 47, 8883. 
25. Hermanson, J. R.; Gunther, M. L.; Belletire, J. L.; Pinhas, A. R. J. Org. Chem. 1995, 60, 1900.

26. Palomo, C.; Aizpurua, J. M.; Cossío, F. P.; García, J. M.; López, M. C.; Oiarbide, M. J. Org. Chem. 1990, 55, 2070.

27. Ono, N.; Kamimura, A.; Kaji, A. Synthesis 1984, 226.

28. Pollini, G. P.; Barco, A.; De Giuli, G. Synthesis 1972, 44.

29. Nakashita, Y.; Hesse, M. Helv. Chim. Acta 1983, 66, 845.

30. Clark, J. H. Chem. Rev. 1980, 80, 429.

31. Grimm, E. L.; Zschiesche, R.; Reissig, H. U. J. Org. Chem. 1985, 50, 5543.

32. Chasar, D. W. Synthesis 1982, 841.

33. Chetia, A.; Saikia, C. J.; Lekhok, K. C.; Boruah, R. C. Tetrahedron Lett. 2004, 45, 2649.

34. Ballini, R.; Barboni, L.; Giarlo, G. J. Org. Chem. 2003, 68, 9173.

35. Ballini, R.; Petrini, M. Synthesis 1986, 1024.

36. Ballini, R.; Petrini, M.; Marotta, E. Synth. Commun. 1987, 17, 543.

37. Ballini, R.; Petrini, M.; Rosini, G. Synthesis 1987, 711.

38. Ballini, R.; Petrini, M.; Marotta, E. Synth. Commun. 1989, 19, 575.

39. Ballini, R. Synthesis 1993, 687.

40. Ballini, R.; Barboni, L.; Bosica, G.; Fiorini, D. Synthesis 2002, 2725.

41. Chamakh, A.; M'hirsi, M.; Villiéras, J.; Lebreton, J.; Amri, H. Synthesis 2000, 295.

42. Ballini, R.; Bosica, G.; Livi, D. Synthesis 2001, 1519.

43. McMurry, J. E.; Melton, J. J. Org. Chem. 1973, 38, 4367.

44. Kalita, D.; Khan, A. T.; Saikia, A. K; Bez, G.; Barua, N. C. Synthesis 1998, 975.

45. Kalita, D.; Khan, A. T.; Barua, N. C.; Bez, G. Tetrahedron 1999, 55, 5177.

46. Crombie, L.; Heavers, A. D. J. Chem. Soc., Perkin Trans. 1 1992, 2683.

47. Adam, W.; Makosza, M.; Saha-Möller, C. R.; Zhao, C.-G. Synlett 1998, 1335.

48. Savilles-Stones, E. A.; Lindell, S. D. Synlett 1991, 591.

49. Ballini, R.; Bosica, G.; Palmieri, A.; Petrini, M.; Pierantozzi, C. Tetrahedron 2003, 59, 7283.

50. Menicagli, R.; Samaritani, S. Tetrahedron 1996, 52, 1425.

51. Miyashita, M.; Tanaka, D.; Shiratani, T.; Irie, H. Chem. Pharm. Bull. 1992, 40, 1614.

52. Miyashita, M.; Awen, B. Z. E.; Yoshikoshi, A. Synthesis 1990, 563.

53. Katoh, T.; Nishide, K.; Node, M.; Ogura, H. Heterocycles 1999, 50, 833.

54. Lakshmaiah, G.; Kawabata, T.; Shang, M.; Fuji, K. J. Org. Chem. 1999, 64, 1699.

55. Haruta, J.; Nishi, K.; Matsuda, S.; Akai, S.; Tamura, Y.; Kita, Y. J. Org. Chem. 1990, 55, 4853.

56. Thominiaux, C.; Roussé, S.; Desmaële, D.; d'Angelo, J.; Riche, C. Tetrahedron: Asymmetry 1999, 10, 2015.

57. Paquette, L. A.; Liu, Z.; Ramsey, C.; Gallucci, J. C. J. Org. Chem. 2005, 70, 8154.

58. Ballini, R.; Castagnani, R.; Petrini, M. J. Org. Chem. 1992, 57, 2160.

59. Rosini, G.; Ballini, R.; Sorrenti, P. Tetrahedron 1983, 39, 4127. 
60. Rosini, G.; Ballini, R.; Petrini, M.; Sorrenti, P. Tetrahedron 1984, 40, 3809.

61. Rosini, G.; Ballini, R.; Zanotti, V. Synthesis 1983, 137.

62. Ballini, R.; Bosica, G. J. Org. Chem. 1994, 59, 5466.

63. Ballini, R.; Astolfi, P. Liebig's Ann. 1996, 1879.

64. Ballini, R.; Bosica, G. Synthesis 1994, 723.

65. Fuji, K.; Zheng, S.-Z.; Node, M.; Hao, X.-J. Chem. Pharm. Bull. 1991, 39, 202.

66. Hao, X.; Node, M.; Fuji, K. J. Chem. Soc., Perkin Trans. 1 1992, 1505.

67. Rosini, G.; Ballini, R.; Petrini, M.; Marotta, E.; Righi, P. Org. Prep. Proc. Int. 1990, 22, 707.

68. Ballini, R.; Bosica, G.; Fiorini, D.; Palmieri, A. Tetrahedron 2005, 61, 8971.

69. Ono, N.; Miyake, H.; Tamura, R.; Kaji, A. Tetrahedron Lett. 1981, 22, 1705.

70. Ono, N.; Miyake, H.; Kaji, A. J. Chem. Soc., Chem. Commun. 1983, 875.

71. Ono, N.; Fujii, M.; Kaji, A. Synthesis 1987, 532.

72. Stach, H.; Hesse, M. Tetrahedron 1988, 44, 1573.

73. Ballini, R.; Fiorini, D.; Gil, M. V.; Palmieri, A. Green Chem. 2003, 5, 475.

74. Ghosh, A. K; Fidanze, S. Org. Lett. 2000, 2, 2405.

75. Jubert, C.; Knochel, P. J. Org. Chem. 1992, 57, 5431.

76. Ballini, R.; Gil, M. V.; Fiorini, D.; Palmieri, A. Synthesis 2003, 665.

77. Bezbarua, M. S.; Saikia, A. K.; Barua, N. C.; Kalita, D.; Ghosh, A. C. Synthesis 1996, 1289.

78. Bartoli, G.; Bosco, M.; Dalpozzo, R.; De Nino, A.; Palmieri, G. Tetrahedron 1994, 50, 9831.

79. Ballini, R. Synlett 1999, 1009.

80. Ballini, R.; Bosica, G. Tetrahedron 1997, 53, 16131.

81. Ballini, R.; Marcantoni, E.; Petrini, M.; Rosini, G. Synthesis 1988, 915.

82. Ballini, R.; Curini, M.; Epifano, F.; Marcotullio, M. C.; Rosati, O. Synlett 1998, 1149.

83. Ballini, R. Bartoli, G. Synthesis 1993, 965.

84. Ballini, R.; Bosica, G. J. Chem. Res. (S) 1993, 435.

85. Ballini, R.; Petrini, M.; Rosini, G. Synthesis 1986, 269.

86. Cookson, R.C.; Ray, P. S. Tetrahedron Lett. 1982, 23, 3521.

87. Ballini, R.; Petrini, M.; Marcantoni, E.; Rosini, G. Synthesis 1988, 231.

88. Kádas, I.; Árvai, G.; Töke, L.; Tóth, G.; Szöllösy, Á.; Bihari, M. Tetrahedron 1994, 50, 2895.

89. Mikló, K.; Jaszberenyi, J. C.; Kádas, I.; Árvai, G.; Töke, L. Tetrahedron Lett. 1996, 37, 3491.

90. Ballini, R.; Bosica, G.; Gigli, F. Tetrahedron 1998, 54, 7573.

91. Ballini, R.; Petrini, M.; Polzonetti, V. Synthesis 1992, 355.

92. Ballini, R.; Barboni, L.; Bosica, G.; Fiorini, D.; Gil, M. V. Synlett 2002, 1706.

93. Cappon, J. J.; Baart, J.; van der Walle, G. A. M.; Raap, J.; Lugtenburg, J. Recl. Trav. Chim. Pays-Bas 1991, 110, 158. 